\title{
Consistent Condom Use among HIV Positive Women Attending Comprehensive Care Centre of Thika Level 5 Hospital, Kenya
}

\author{
Anne G. Macharia ${ }^{1}$, Yeri Kombe ${ }^{2}$, Peter Mwaniki ${ }^{1}$ \\ ${ }^{1}$ Institute of Tropical Medicine and Infectious Diseases, Jomo Kenyatta University of Agriculture and \\ Technology, Nairobi, Kenya \\ ${ }^{2}$ Center for Public Health Research, Kenya Medical Research Institute, Nairobi, Kenya \\ Email: "muthoniann05@yahoo.com
}

Received 12 June 2015; accepted 16 August 2015; published 19 August 2015

Copyright (C) 2015 by authors and Scientific Research Publishing Inc.

This work is licensed under the Creative Commons Attribution International License (CC BY).

http://creativecommons.org/licenses/by/4.0/

(c) (i) Open Access

\section{Abstract}

Background: Condoms offer protection against human immunodeficiency virus (HIV) transmission when used correctly and consistently. Many HIV infected people do not use condom regularly, thus leading to new HIV infections and re-infections. In Kenya, condom use is considered to be low and HIV prevalence is high among women aged 15 - 49 years where utilization of condoms among HIV positive women has not been studied. Objectives: The study aimed at determining the prevalence of consistent condom use among HIV positive women aged 18 - 49 years and to investigate the variables associated with it. Methods: A mixed method of study design (qualitative and quantitative approaches) was employed. A total of 422 participants were selected randomly and interviewed using a pre-tested structured questionnaire. Three (3) focus group discussions with 8 participants in each group were conducted. Chi-square test $(p<0.05)$ and odds ratio with corresponding $\mathbf{9 5 \%}$ confidence interval were computed to establish the association between consistent condom use and independent variables. Binary logistic regression model was used to identify variables independently associated with consistent condom use. Qualitative data were transcribed and coded and then analysed thematically. Results: Consistent condom use among sexually active HIV positive women was found to be $57.4 \%$ (95\%CI: $52.7 \%-62.1 \%)$. The stepwise logistic regression revealed that attending tertiary education $[\mathrm{aOR}=2.54 ; 95 \% \mathrm{CI}=1.30-4.95 ; \mathrm{P}=0.006]$, disclosing HIV status $[\mathrm{aOR}=2.27 ; 95 \% \mathrm{CI}=1.27-4.06 ; \mathrm{P}=0.005]$, having an HIV negative partner $[\mathrm{aOR}=4.23 ; 95 \% \mathrm{CI}=1.99-8.98 ; \mathrm{P}<0.001]$, not taking alcohol $[\mathrm{aOR}=1.72 ; 95 \% \mathrm{CI}=1.10-2.69 ; \mathrm{P}=$ 0.017], never encountered resistance to use condom by partners $[\mathrm{aOR}=1.87 ; 95 \% \mathrm{CI}=1.15-3.03$; $P=0.011]$ and perceived risk of contracting STIs $[\mathrm{aOR}=2.11 ; 95 \% \mathrm{CI}=1.12-3.97 ; \mathrm{P}=0.021]$ as factors independently associated with consistent condom use. Conclusion: This study shows that there is still low prevalence of consistent condom use among HIV positive women. More education,

${ }^{*}$ Corresponding author. 
campaigning and sensitization should be tailored among HIV positive women during counseling so as to avoid re-infection and transmission of infections.

\title{
Keywords
}

\author{
Consistent Condom Use, HIV Positive Women, HIV Status
}

\section{Introduction}

Condoms are shown to be over 90\% effective in preventing pregnancy, the transmission of HIV and other sexually transmitted diseases (STDs) [1]. Several studies done among discordant couples who engaged in regular sexual activity support this finding [2] [3]. Condoms have been and are an integral part of HIV preventive measures worldwide and many countries have designed programs that encourage people to use them [4]. Despite this concerted effort, many people don't use condoms consistently [5].

HIV is one of the world's leading pandemics worldwide [6]. More than 33.4 million people are infected with the virus [5]. Sub Saharan Africa (SSA) remains the most affected region; 22.4 million people living with HIV by the year 2008 were from SSA [5]. In Kenya more than 1.4 (7.4\%) million people are living with HIV and 60\% of the infected are women [7]. The disease still poses a significant challenge to this low income country [8], despite various strategies that have been put in place to reduce its incidence such as media campaigns and condom distribution among others.

The use of highly active antiretroviral therapy (HAART) has been useful in reducing morbidity and mortality from HIV/AIDS [9]. Apart from the beneficial clinical effects, treatment may have unintended effects on sexual behaviour. Some evidence suggests that since HAART became available, the prevalence of unprotected sex [10] and the incidence of sexually transmitted infections (STIs) [11] including HIV have increased. Moreover, when engaging in sex without condom, those with high viral load or low CD4 count before or at the initiation of ART have the potential to infect their sero-negative sexual partner or at risk of acquiring drug resistant viral strains from their sexual partner who are already infected [12] [13].

Despite the recognition given to condom as a major mode of prevention for diseases that are transmitted through sexual intercourse, little is known about the practice of condom use among HIV infected people in developing countries like Kenya. The focus of HIV prevention efforts in most countries, including Kenya is largely on people uninfected with HIV and the sexual risky practice by HIV infected persons has not received due attention. This study therefore aimed to establish the prevalence of self-reported condom use among women living with HIV and to investigate the variables associated with consistent condom use.

\section{Methods and Materials}

\subsection{Study Setting}

The study was conducted at the Comprehensive Care Center (CCC) of Thika Level 5 Hospital (TL5H). It is located in Thika town, which is an industrial city Centre in Kiambu County. It is located 40 kilometers North East of Nairobi city and has a population of 448,099. TL5H is a provincial referral hospital which serves the wider Kiambu county and neighboring counties. Prevalence of HIV in Thika is highest in the former Central province at 7.6\% [14]. Moreover, it has a comprehensive care center that handles HIV/AIDS patients, dispensing medicine and counseling.

\subsection{Study Design}

A mixed method study design using qualitative and quantitative approaches was conducted.

\subsection{Sample Size and Sampling Procedures}

The study included HIV positive women aged 18 to 49 years. The sample size for quantitative research was calculated using single population formula (Fischer et al., 1998) as the study was estimating the proportion in a 
single population $\left(n=Z^{2} p(1-p) / d^{2}\right)$. The following assumptions were considered: 95\% confidence interval, $5 \%$ margin of error, since the proportion (p) of consistent condom use among HIV positive women was not known, p was taken to be $50 \%$. By adding $10 \%$ non-response rate, the final sample size was 422 . All the clients in the CCC register or booking catalogue in the clinic during the study period was used as the sampling frame. Their clinic assigned numbers were entered into a computer and the required sample size was selected randomly using SPSS software. Furthermore, to supplement the quantitative data 3 focus group discussions with 8 participants in each group selected purposively were undertaken.

\subsection{Data Collection Tool}

A pre-tested structured questionnaire was used for data collection. The study participants were interviewed after they were through with the clinic procedures and consent been obtained. The data was collected by trained nurses. The dependent variable was "consistent condom use" (use of condom in every sexual encounter in the last six months preceding the study). The independent variables included were socio-demographic characteristics; relational and behavioural factors such as type of partners, disclosure of HIV status to partner, sexual partner's HIV status, taking alcohol; awareness, attitude and practice towards condom use and etc.

\subsection{Data Analysis Method}

Data captured in questionnaires was entered into a computer database designed using MS Excel application. Data cleaning and validation was performed in order to achieve a clean dataset that was exported into a Statistical Package format (SPSS Version 20.0) ready for analysis. Descriptive analysis was done using frequencies and proportions. Pearson's Chi-square test was used to establish the association between the dependent variable (consistent condom use) and independent variables in order to determine which ones had significant association. Odds ratio (OR) with corresponding 95\% confidence interval (95\%CI) were estimated. The level of statistical significance was set at p-value $<0.05$. Binary logistic regression analysis was performed to identify variables predictive of consistent condom use.

\subsection{Ethical Considerations}

Approval to carry out the study was sought and obtained from Kenya Medical Research Institute (KEMRI), Ethical Review Committee. Written consent was obtained from all study participants after a detailed explanation of the purpose of the study.

\section{Results}

\subsection{Consistent Condom Use}

Figure 1 illustrates the prevalence of consistent condom use and 57.4\% (95\%CI: 52.7\% to 62.1\%) participants reported that they used condom each time during sexual encounter within the past 6 months.

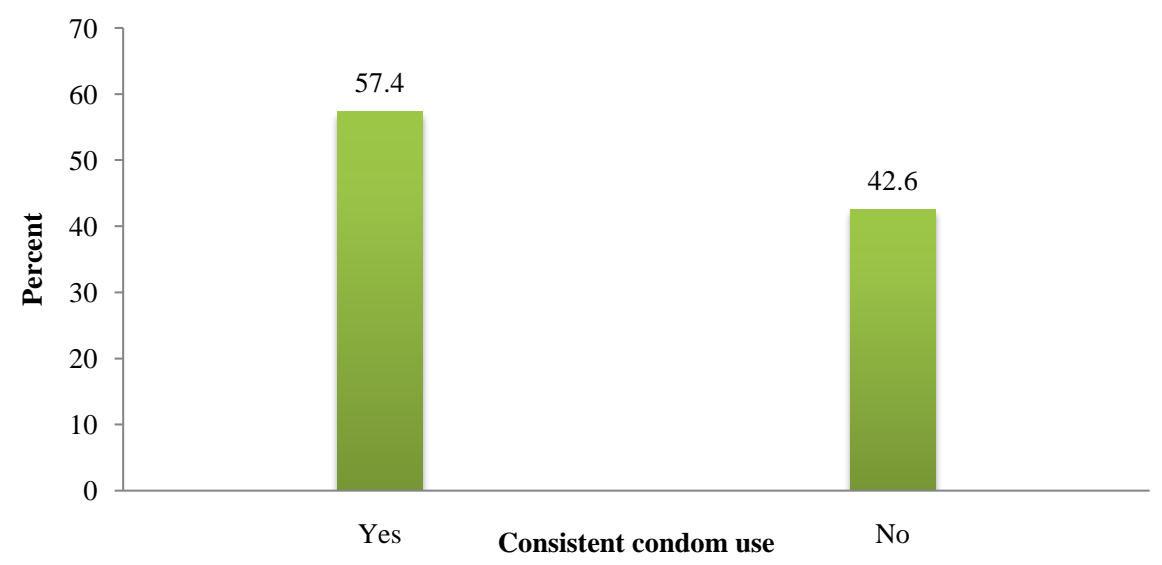

Figure 1. Percentage of consistent condom use. 


\subsection{Bivariate Analysis of Factors Associated with Consistent Condom Use}

Table 1 shows the association of socio-demographic characteristics, behavioral/relational factors and awareness/attitude towards condoms with consistent use of condoms. There was a significant higher proportion of participants with consistent condom use among those attended tertiary education $(74.4 \%)$ [OR $=2.12$; 95\% $\mathrm{CI}=$ 1.19 - 3.80; $\mathrm{P}=0.011$ ] than those attended primary education (57.7\%). Respondents who knew their HIV positive status recently (less than 1 year) had reduced proportion of consistent condom use (48.6\%) than those who knew their HIV positive for more than 3 years (61.1\%). However, this difference was not statistically significant [OR $=0.60 ; 95 \% \mathrm{CI}=0.36-1.03 ; \mathrm{P}=0.062]$.

The proportion of consistent condom use was significantly higher among respondents with regular relationships $(61.4 \%)$ compared to those who had casual partnerships (41.0\%), [OR $=2.29$; $95 \% \mathrm{CI}=1.41-3.74 ; \mathrm{P}=$ 0.001]. Respondents who disclosed their HIV status to partners had significantly increased prevalence of condom use consistently $(61.8 \%)$, $[\mathrm{OR}=2.53 ; 95 \% \mathrm{CI}=1.54-4.15 ; \mathrm{P}<0.001]$ than those who indicated otherwise (39.0\%). There was a significant increase of consistent condom use among participants whose partners were HIV negatives (81.4\%), [OR = 5.05; 95\%CI = 2.59 - 9.85; $\mathrm{P}<0.001]$ and HIV positives $(59.4 \%)$ [OR = 1.69; $95 \% \mathrm{CI}=1.11-2.57 ; \mathrm{P}=0.015]$ compared to those who didn't know their partners HIV status $(43.5 \%)$. The prevalence of consistent condom use was significantly more among respondents whose sexual partners never resisted using condom $(64.4 \%)$ [OR $=1.57 ; 95 \% \mathrm{CI}=1.04-2.36$; $\mathrm{P}=0.032]$ than those whose partners ever resisted (53.6\%). Women who reported never used to take alcohol were significantly more likely to use condom consistently $(64.0 \%)[\mathrm{OR}=1.98 ; 95 \% \mathrm{CI}=1.33-2.94 ; \mathrm{P}=0.001]$ compared to those who reported otherwise (47.3\%).

Respondents who attended any condom demonstration sessions were significantly more consistent with condom use during sexual act (58.7\%) $[\mathrm{OR}=3.70 ; 95 \% \mathrm{CI}=1.29-10.57 ; \mathrm{P}=0.009]$ compared to those who didn't attend (27.8\%). The table further shows that women who indicated that consistent condom use can protect against STIs had significantly higher prevalence of consistent condom use $(59.5 \%)$ [OR $=1.88$; 95\%CI $=1.07$ 3.30; $\mathrm{P}=0.026$ ] compared to those who indicated otherwise (43.9\%).

\subsection{Factors Associated with Consistent Condom Use}

Multiple logistic regression was applied to identify the variables independently associated with consistent condom use in the previous 6 months among HIV positive women (Table 2). Significant factors during bivariate analysis were considered together in multivariate analysis. Upon fitting the factors using binary logistic regression and specifying "backward conditional" method with removal at $\mathrm{P}<0.05$, seven (7) factors remained in the final analysis as shown in Table 2.

Respondents with tertiary level of education were 2.5 times more likely to report consistent use of condoms $[\mathrm{aOR}=2.54 ; 95 \% \mathrm{CI}=1.30-4.95 ; \mathrm{P}=0.006]$ than those who attended primary education. Women who disclosed their HIV status to partner were about 2 fold more likely to use condom consistently than women who did not [aOR $=2.27 ; 95 \% \mathrm{CI}=1.27$ - 4.06; $\mathrm{P}=0.005]$. Respondents who had HIV negative partners were about 4 times more likely to use condom consistently [aOR $=4.23 ; 95 \% \mathrm{CI}=1.99-8.98 ; \mathrm{P}<0.001]$ compared to those who did not know their partner's status. Women who attended any condom demonstration sessions were 3.17 fold [aOR $=3.17 ; 95 \% \mathrm{CI}=1.01-9.98 ; \mathrm{P}=0.048$ ] more likely to use it consistently than those who didn't attend. Respondents who reported no alcohol abuse were 1.72 times more likely to use condoms consistently [aOR $=1.72 ; 95 \% \mathrm{CI}=1.10-2.69 ; \mathrm{P}=0.017]$ than those who reported consuming alcohol. Consistent condom use was found to be about 2 times more among participants whose partners never resisted to use condom [aOR = 1.87; 95\%CI $=1.15-3.03 ; \mathrm{P}=0.011$ ]. Women who indicated that consistent use of condom can protect STIs were 2.11 fold more likely to use condom consistently than those who reported otherwise $[\mathrm{aOR}=2.11 ; 95 \% \mathrm{CI}=$ 1.12 - 3.97; $\mathrm{P}=0.021]$.

\section{Discussion}

The findings of the study showed that the proportion of consistent condom use was $57.4 \%$. This figure is similar to other studies carried out among sexually active HIV positive women in Ethiopia at 56.7\% [15], in Uganda at $55 \%$ [16] and in Italy 60\% [17]. However, it is quite low compared to findings from studies conducted among ART patients in other settings. For example condom use among ART patients in India was reported 89\% [18] 
Table 1. Bivariate analysis of factors associated consistent condom use among HIV positive women attending Thika Level 5 Hospital, Kenya, 2015.

\begin{tabular}{|c|c|c|c|c|c|c|c|}
\hline \multirow{2}{*}{ Variables } & \multirow{2}{*}{ Total, n (\%) } & \multicolumn{2}{|c|}{ Consistent condom use } & \multirow{2}{*}{ OR } & \multicolumn{2}{|c|}{$95 \% \mathrm{CI}$} & \multirow{2}{*}{$\begin{array}{c}\chi^{2} \text { test } \\
\text { P value }\end{array}$} \\
\hline & & Yes, n (\%) & No, n (\%) & & Lower & Upper & \\
\hline \multicolumn{8}{|c|}{ Socio-demographic characteristics } \\
\hline \multicolumn{8}{|c|}{ Age in years } \\
\hline $18-29$ & $112(26.4 \%)$ & $66(58.9 \%)$ & $46(44.1 \%)$ & 1.01 & 0.59 & 1.74 & 0.965 \\
\hline $30-39$ & $210(49.4 \%)$ & $117(55.7 \%)$ & $93(44.3 \%)$ & 1.15 & 0.72 & 1.86 & 0.556 \\
\hline $40-49$ & $103(24.2 \%)$ & $61(59.2 \%)$ & $42(40.8 \%)$ & 1.00 & & & \\
\hline \multicolumn{8}{|c|}{ Residence } \\
\hline Thika & $311(73.2 \%)$ & $184(59.2 \%)$ & $127(40.8 \%)$ & 1.30 & 0.85 & 2.01 & 0.228 \\
\hline Outside Thika & $114(26.8 \%)$ & $60(52.6 \%)$ & $54(47.4 \%)$ & 1.00 & & & \\
\hline \multicolumn{8}{|c|}{ Level of Education } \\
\hline Primary & $194(45.6 \%)$ & $112(57.7 \%)$ & $82(42.3 \%)$ & 1.00 & & & \\
\hline Secondary & $153(36.0 \%)$ & $74(48.4 \%)$ & $79(51.6 \%)$ & 0.69 & 0.45 & 1.05 & 0.083 \\
\hline Tertiary & $78(18.4 \%)$ & $58(74.4 \%)$ & $20(25.6 \%)$ & 2.12 & 1.19 & 3.80 & 0.011 \\
\hline \multicolumn{8}{|c|}{ Marital status } \\
\hline Single & $130(30.6 \%)$ & $72(55.4 \%)$ & $58(44.6 \%)$ & 1.07 & 0.59 & 1.93 & 0.825 \\
\hline Married & $228(53.6 \%)$ & $136(59.6 \%)$ & $92(40.4 \%)$ & 1.27 & 0.74 & 2.20 & 0.388 \\
\hline Divorced/Widowed & $67(15.8 \%)$ & $36(53.7 \%)$ & 31 (46.3\%) & 1.00 & & & \\
\hline \multicolumn{8}{|c|}{ Occupation } \\
\hline Un-employed & $97(22.8 \%)$ & $56(57.7 \%)$ & $41(42.3 \%)$ & 1.02 & 0.64 & 1.61 & 0.942 \\
\hline Employed & $328(77.2 \%)$ & $188(57.3 \%)$ & $140(42.7 \%)$ & 1.00 & & & \\
\hline \multicolumn{8}{|c|}{ Religion } \\
\hline Christian Protestant & 218 (51.3\%) & $121(55.5 \%)$ & $97(44.5 \%)$ & 0.97 & 0.35 & 2.70 & 0.954 \\
\hline Christian Catholic & 191 (44.9\%) & 114 (59.7\%) & $77(40.3 \%)$ & 1.15 & 0.41 & 3.22 & 0.788 \\
\hline Muslim & $16(3.8 \%)$ & $9(56.2 \%)$ & $7(43.8 \%)$ & 1.00 & & & \\
\hline \multicolumn{8}{|c|}{ The duration since tested positive in years } \\
\hline$<1$ & $74(17.4 \%)$ & $36(48.6 \%)$ & $38(51.4 \%)$ & 0.60 & 0.36 & 1.03 & 0.062 \\
\hline 1 to 3 & $130(30.6 \%)$ & $73(56.2 \%)$ & $57(43.8 \%)$ & 0.82 & 0.53 & 1.27 & 0.364 \\
\hline$>3$ & $221(52.0 \%)$ & $135(61.1 \%)$ & $86(38.9 \%)$ & 1.00 & & & \\
\hline \multicolumn{8}{|c|}{ Enrolment at the CCC for the first time } \\
\hline Less than 3 months & $43(10.1 \%)$ & $27(62.8 \%)$ & $16(37.2 \%)$ & 1.28 & 0.67 & 2.48 & 0.455 \\
\hline 6 - 12 months & $65(15.3 \%)$ & $37(56.9 \%)$ & $28(43.1 \%)$ & 1.01 & 0.59 & 1.72 & 0.983 \\
\hline$>1$ year & $317(74.6 \%)$ & $180(56.8 \%)$ & $137(43.2 \%)$ & 1.00 & & & \\
\hline \multicolumn{8}{|c|}{ Behavioural and relational characteristics } \\
\hline \multicolumn{8}{|c|}{ Sexual relationships } \\
\hline Regular partnership & $342(80.5 \%)$ & $210(61.4 \%)$ & $132(38.6 \%)$ & 2.29 & 1.41 & 3.74 & 0.001 \\
\hline Casual partnership & $83(19.5 \%)$ & $34(41.0 \%)$ & $49(59.0 \%)$ & 1.00 & & & \\
\hline \multicolumn{8}{|c|}{ Frequency of sexual intercourse engagement per week } \\
\hline One to three times & $331(77.9 \%)$ & $186(56.2 \%)$ & 145 (43.8\%) & 0.80 & 0.50 & 1.27 & 0.340 \\
\hline
\end{tabular}




\section{Continued}

\begin{tabular}{|c|c|c|c|c|c|c|c|}
\hline Four and above & $94(22.1 \%)$ & $58(61.7 \%)$ & $36(38.3 \%)$ & 1.00 & & & \\
\hline \multicolumn{8}{|c|}{ Disclosure of sero-status to partner } \\
\hline Yes & $343(80.7 \%)$ & $212(61.8 \%)$ & $131(38.2 \%)$ & 2.53 & 1.54 & 4.15 & $<0.001$ \\
\hline No & $82(19.3 \%)$ & $32(39.0 \%)$ & $50(61.0 \%)$ & 1.00 & & & \\
\hline \multicolumn{8}{|c|}{ HIV status of the partner } \\
\hline HIV negative & $70(16.5 \%)$ & $57(81.4 \%)$ & $13(18.6 \%)$ & 5.05 & 2.59 & 9.85 & $<0.001$ \\
\hline HIV positive & $170(40.0 \%)$ & $101(59.4 \%)$ & $69(40.6 \%)$ & 1.69 & 1.11 & 2.57 & 0.015 \\
\hline Don't know & $185(43.5 \%)$ & $86(46.5 \%)$ & $99(53.5 \%)$ & 1.00 & & & \\
\hline \multicolumn{8}{|c|}{ Does your sexual partner(s) sometimes resist use of condom? } \\
\hline Yes & $276(64.9 \%)$ & $148(53.6 \%)$ & $128(46.4 \%)$ & 1.00 & & & \\
\hline No & 149 (35.1\%) & $96(64.4 \%)$ & $53(35.6 \%)$ & 1.57 & 1.04 & 2.36 & 0.032 \\
\hline \multicolumn{8}{|c|}{ Any substance/alcohol use } \\
\hline Yes & $167(39.3 \%)$ & $79(47.3 \%)$ & $88(52.7 \%)$ & 1.00 & & & \\
\hline No & $258(60.7 \%)$ & $165(64.0 \%)$ & $93(36.0 \%)$ & 1.98 & 1.33 & 2.94 & 0.001 \\
\hline \multicolumn{8}{|c|}{ Knowledge and attitude } \\
\hline \multicolumn{8}{|c|}{ Receiving adherence counselling on condom use during CCC visits } \\
\hline Always & $314(73.9 \%)$ & $185(58.9 \%)$ & $129(41.1 \%)$ & 1.00 & 0.37 & 2.71 & 0.994 \\
\hline Sometimes & $94(22.1 \%)$ & $49(52.1 \%)$ & $45(47.9 \%)$ & 0.76 & 0.27 & 2.17 & 0.611 \\
\hline Never & $17(4.0 \%)$ & $10(58.8 \%)$ & $7(41.2 \%)$ & 1.00 & & & \\
\hline \multicolumn{8}{|c|}{ Attending any condom demonstration session } \\
\hline Yes & $407(95.8 \%)$ & $239(58.7 \%)$ & $168(41.3 \%)$ & 3.70 & 1.29 & 10.57 & 0.009 \\
\hline No & $18(4.2 \%)$ & $5(27.8 \%)$ & $13(72.2 \%)$ & 1.00 & & & \\
\hline \multicolumn{8}{|c|}{ Have ever heard about female condoms } \\
\hline Yes & $378(88.9 \%)$ & 217 (57.4\%) & $161(42.6 \%)$ & 1.00 & 0.54 & 1.84 & 0.996 \\
\hline No & $47(11.1 \%)$ & $27(57.4 \%)$ & $20(42.6 \%)$ & 1.00 & & & \\
\hline \multicolumn{8}{|c|}{ Condoms are really safe and effective to prevent HIV infection and re-infection } \\
\hline Yes & 389 (91.5\%) & $228(58.6 \%)$ & $161(41.4 \%)$ & 1.77 & 0.89 & 3.52 & 0.100 \\
\hline No & $36(8.5 \%)$ & $16(44.4 \%)$ & $20(55.6 \%)$ & 1.00 & & & \\
\hline \multicolumn{8}{|c|}{ Consistent use of condom can protect sexually transmitted diseases } \\
\hline Yes & $368(86.6 \%)$ & $219(59.5 \%)$ & $149(40.5 \%)$ & 1.88 & 1.07 & 3.30 & 0.026 \\
\hline No & $57(13.4 \%)$ & $25(43.9 \%)$ & $32(56.1 \%)$ & 1.00 & & & \\
\hline \multicolumn{8}{|c|}{ Condoms should be used every time, from start to finish of each sexual encounter } \\
\hline Agree & 399 (93.9\%) & $232(58.1 \%)$ & 167 (41.9\%) & 1.62 & 0.73 & 3.59 & 0.231 \\
\hline Disagree & $26(6.1 \%)$ & $12(46.2 \%)$ & $14(53.8 \%)$ & 1.00 & & & \\
\hline \multicolumn{8}{|c|}{ Only men decide whether to use a condom } \\
\hline True & $47(11.1 \%)$ & $21(44.7 \%)$ & $26(55.3 \%)$ & 0.56 & 0.31 & 1.03 & 0.061 \\
\hline False & 378 (88.9\%) & 223 (59.0\%) & 155 (41.0\%) & 1.00 & & & \\
\hline
\end{tabular}

Abbreviations: $\mathrm{OR}=$ Odds Ratio, CI = Confidence Interval.

although the subjects in that study were financing treatment themselves, so they might have been economically stable. Similar relatively higher levels of condom use have been reported among HAART patients in developed 
Table 2. Multivariate analysis of factors associated with consistent condom use among HIV positive women.

\begin{tabular}{|c|c|c|c|c|}
\hline \multirow{2}{*}{ Variable } & \multirow{2}{*}{ AOR } & \multicolumn{2}{|c|}{$95 \% \mathrm{CI}$} & \multirow{2}{*}{$\begin{array}{c}\chi^{2} \text { test } \\
\text { P value }\end{array}$} \\
\hline & & Lower & Upper & \\
\hline \multicolumn{5}{|c|}{ Level of Education } \\
\hline Primary & 1.00 & & & \\
\hline Secondary & 0.88 & 0.54 & 1.42 & 0.599 \\
\hline Tertiary & 2.54 & 1.30 & 4.95 & 0.006 \\
\hline \multicolumn{5}{|c|}{ Disclosure of sero-status to partner } \\
\hline Yes & 2.27 & 1.27 & 4.06 & 0.005 \\
\hline No & 1.00 & & & \\
\hline \multicolumn{5}{|c|}{ HIV status of the partner } \\
\hline HIV negative & 4.23 & 1.99 & 8.98 & $<0.001$ \\
\hline HIV positive & 1.13 & 0.69 & 1.85 & 0.428 \\
\hline Don't know & 1.00 & & & \\
\hline \multicolumn{5}{|c|}{ Attending any condom demonstration session } \\
\hline Yes & 3.17 & 1.01 & 9.98 & 0.048 \\
\hline No & 1.00 & & & \\
\hline \multicolumn{5}{|c|}{ Does your sexual partner(s) sometimes resist use of condom? } \\
\hline Yes & 1.00 & & & \\
\hline No & 1.87 & 1.15 & 3.03 & 0.011 \\
\hline \multicolumn{5}{|c|}{ Any substance/alcohol use } \\
\hline Yes & 1.00 & & & \\
\hline No & 1.72 & 1.10 & 2.69 & 0.017 \\
\hline \multicolumn{5}{|c|}{ There are risks involved for failure to use condoms when partner is HIV positive } \\
\hline Yes & 2.11 & 1.12 & 3.97 & 0.021 \\
\hline No & 1.00 & & & \\
\hline
\end{tabular}

Abbreviations: $\mathrm{aOR}=$ Adjusted Odds Ratio, $\mathrm{CI}$ = Confidence Interval.

countries [19] [20]. Differences across these studies could be due to the differences in research methods, the specific behaviors, recall periods and/or socioeconomic status of the study population.

Higher education level was a predictive factor for consistent condom use in this study. This finding concurs with studies done in Addis Ababa public hospitals [21] and Ghana [22] which reported that participants with secondary education or higher were more likely to use condoms consistently than those with primary level of education. This might be because of the participants' knowledge towards condom use and concerns to prevent resistant strains and other STIs that make them to use condom consistently. In addition, this could be the high self-efficacy for condom-use among people who have secondary- or tertiary-level education [23] [24].

HIV positive women who had disclosed their HIV status were more likely to use condom consistently than those who did not disclose to their partner. This finding is in consonance with previous studies in Ghana [22]. This suggests that disclosure of HIV status to a partner may be important to get support from family or partners. Some research has found that increased HIV/AIDS stigma directly or indirectly predicted unsafe sexual behaviour [25]-[27] and people who perceived more HIV related stigma were less likely to disclose their HIV status to partners [28].

In this study having an HIV negative partner was associated with approximately 4 times increased odds of consistently using condoms compared to those who did not know their partner's status. This finding corroborates previous research conducted with predominantly white sero-discordant relationships/couples in France [29] 
which found sero-discordant couples were 6.1 times more likely to report consistent condom use. Moreover, inquiring about a partner's HIV status has been associated with an increase in the likelihood of negotiating safer sex practices [30]. Since awareness of partners' HIV status is associated with consistent condom, it could be suggested that even in multiple partnerships, awareness of partners' status is protective against HIV transmission.

Findings of this study indicate that drinking alcohol has a statistically significant effect on consistent condom use. Women who do not drink alcohol are more likely to use condoms consistently than those who drink alcohol. Similarly, in a meta-analysis based on 27 studies demonstrated that any alcohol consumption, problematic drinking, and alcohol use in sexual contexts were all found to be significantly associated with unprotected sex among people living with HIV/AIDS (PLWHA) [31]. There may be many reasons for this association. Alcohol can act directly on the brain to reduce inhibitions and diminish risk perception and hence produce a tendency towards high-risk sexual behavior. So effort should be strengthened towards reduction of alcohol use among these particular clients.

As expected consistent condom use was found to be more among participants whose partners never resisted using condom. It has also been indicated that among HIV positive women, unprotected intercourse has been associated with perception of little personal control over their male partner's use of condoms, less assertiveness and partner's desire to have children [32]. Gender inequality might reflect a male resistance to use condoms, disregarding awareness of the women's HIV sero-status. This attitude has been previously described in studies conducted both in young and older women [33] and underlines the difficulty for women with HIV to negotiate safer sex practices. In addition, husbands and male partners may resist use of condoms in marital and steady relationships because sex ought to be natural and based on trust.

The study also showed that those participants who thought consistent condom use can prevent sexually transmitted diseases were more likely to use condom consistently than those who did not think so. Furthermore, the study has revealed that women who had attended any condom demonstration sessions were more likely to use it consistently which could be explained that respondents were well confident about using condoms.

From the focus group discussions (FGDs), the major impediment to use condom consistently mentioned by the participants were alcohol influence, fear of mistrust, lack of negotiation skills, non-disclosure of HIV positive status to partner and spoiling of pleasure. Some of these barriers were strongly supported by the quantitative data of the study. Moreover, qualitative findings regarding the beliefs, myths and misconceptions associated with non-condom use mentioned by participants were condoms are not $100 \%$ safe (breaks and having aeration pores), promiscuity among woman for carrying condoms and being illegal among some religions (Catholics). The claim that condoms can break is enough to have a negative attitude to condom use. Women's negative attitude to condom use may compromise safer sex measures which is consistent with previous findings [34] [35]. Some of the participants from the FGDs also indicated that fear been seen buying from chemists, misuse of condoms especially those in public facilities and inacessibility/unavailability especially in remote localities were the main factors affecting the use of condoms.

\section{Limitations and Strengths of the Study}

This study was conducted with a certain limitation. Consistent condom use was assessed based on self-reported information which is subject to socially desirable bias and recall bias. In addition, the generalizability of this study may be limited because HIV positive individuals who visited the HIV clinic might be different from those who did not. Despite these limitations, this study has significant public health relevance and the data could inform intervention strategies to reduce risky sexual behaviour among HIV positive persons on ART.

As to the strengths of this study, the respondents have been selected by random sampling technique with relatively large sample size. Precautions have been taken in selection of experienced female data collectors to address social desirability bias and in order to minimize the recall bias, 6 month recall period was used. Also it was supplemented by qualitative data (FGDs) for more solicitude of ideas about sensitive issues.

\section{Conclusion}

In this study consistent condom utilization is still low which needs an intervention through awareness campaigns by involvement of ministry for health and other concerned stakeholders. Advanced level of education, disclosing HIV status, having a HIV-negative partner, non consumption of alcohol, non resistance to condom use by part- 
ner(s) and perceived risk of contracting STIs if condoms are not used consistently were the identified predictors to consistent condoms use. In light of this, increasing awareness about the importance of using condom consistently during counseling can be a powerful means of fostering consistent condom use among HIV positive women, in order to reduce HIV transmission and re-infection.

\section{Acknowledgements}

The authors acknowledge to all women who participated in this study for their time and willingness. The authors also give special thanks to the manager and all staff members of Comprehensive Care Centre of Thika Level 5 Hospital for their cooperation during the collection of data for this study and allowing us to conduct this research.

\section{Conflict of Interests}

The authors declare that they have no competing interests.

\section{References}

[1] Stammers, T. (2005) As Easy as ABC? Primary Prevention of Sexually Transmitted Infections. Postgraduate Medical Journal, 81, 273-275. http://dx.doi.org/10.1136/pgmj.2004.027722

[2] Weller, S. and Davis, K. (2003) Condom Effectiveness in Reducing Heterosexual HIV Transmission. Oxford. The Cochrane Library, Issue 2.

[3] Macaluso, M., Lawson, M.L., Hortin, G., Duerr, A., Hammond, K.R., Blackwell, R. and Bloom, A. (2003) Efficacy of the Female Condom as a Barrier to Semen during Intercourse. American Journal of Epidemiology, 157, 289-297. http://dx.doi.org/10.1093/aje/kwf212

[4] Versteeg, M. and Murray, M. (2008) Condom Use as Part of the wider HIV Prevention Strategy: Experiences from Communities in the North West Province, South Africa. Journal of Social Aspects of HIV/AIDS, 5, 83-93. http://dx.doi.org/10.1080/17290376.2008.9724905

[5] Joint United Nations Programme on HIV/AIDS (UNAIDS) (2008) Report on the Global AIDS Epidemic. Geneva.

[6] WHO (2010) Scaling up Priority HIV/AIDS Interventions in the Health Sector. http://whqlibdoc.who.int/publications/2010/97892415 00395 eng.pdf

[7] Kenya AIDS Indicator Survey (2007) Prevalence of HIV in Kenya. 44-46.

[8] World Bank (2008) Country Classifications: Country Groups.

[9] Dore, G.J. and Cooper, D.A. (2006) HAART’s First Decade: Successbrings Further Challenges. Lancet, 368, 427-428. http://dx.doi.org/10.1016/S0140-6736(06)69128-9

[10] Chen, S.Y., Gibson, S., Katz, M.H., Klausner, J.D., Dilley, J.W., Schwarez, S.K., Kellogg, T.A. and McFarland, W. (2002) Continuing Increases in Sexual Risk Behaviour and Sexually Transmitted Diseases among Men Who Have Sex with Men. American Journal of Public Health, 92, 1387-1388. http://dx.doi.org/10.2105/AJPH.92.9.1387-a

[11] Stolte, I.G., Dukers, N.H., de Wit, J.B., Fennema, J.S. and Coutinho, R.A. (2001) Increase in Sexually Transmitted Infections among Homosexual Men in Amsterdam in Relation to HAART. Sexually Transmitted Infections, 77, 184-186. http://dx.doi.org/10.1136/sti.77.3.184

[12] Donnell, D., Baeten, J.M., Kiarie, J., Thomas, K.K., Stevens, W., Cohen, C.R., et al. (2010) Heterosexual HIV-1 Transmission after Initiation of Antiretroviral Therapy: A Prospective Cohort Analysis. The Lancet, 375, 2092-2098. http://dx.doi.org/10.1016/S0140-6736(10)60705-2

[13] Cohen, M.S., Chen, Y.Q., McCauley, M., Gamble, T., Hosseinipour, M.C., Kumarasamy, N., et al. (2011) Prevention of HIV-1 Infection with Early Antiretroviral Therapy. The New England Journal of Medicine, 365, 493-505. http://dx.doi.org/10.1056/NEJMoa1105243

[14] National AIDS/STI Contol Programme (NASCOP) Kenya (2007) Kenya AIDS Indicator Survey. http://www.aidskenya.org

[15] Alene, K.A. (2014) Consistent Condom Use among Sexually Active HIV-Positive Women in Amhara Region, Ethiopia. Open Access Journal of Contraception, 5, 85-90. http://dx.doi.org/10.2147/OAJC.S72683

[16] Bateganya, M., Colfax, G., Shafer, L.A., Kityo, C., Mugyenyi, P., Serwadda, D., et al. (2005) Antiretroviral Therapy and Sexual Behavior: A Comparative Study between Antiretroviral-Naive and -Experienced Patients at an Urban HIV/ AIDS Care and Research Center in Kampala, Uganda. AIDS Patient Care STDS, 19, 760-768. http://dx.doi.org/10.1089/apc.2005.19.760 
[17] Cicconi, P., d’Arminio Monforte, A., Castagna, A., Quirino, T., Alessandrini, A., Gargiulo, M., et al. (2013) Inconsistent Condom Use among HIV-Positive Women in the "Treatment as Prevention Era": Data from the Italian DIDI Study. Journal of the International AIDS Society, 16, Article ID: 18591. http://dx.doi.org/10.7448/IAS.16.1.18591

[18] Avina, S., Gupta, I., Pujari, S., Sengar, A.K., Garg, R. and Weiss, E. (2006) Examining Adherence and Sexual Behaviour among Patients on Antiretroviral Therapy in India. Horizons Final Report, Population Council, Washington DC.

[19] Wilson, T.E., Gore, M.E., Greenblatt, R., Cohen, M., Minkoff, H., Silver, S., et al. (2004) Changes in Sexual Behaviour among HIV-Infected Women after Initiation of HAART. American Journal of Public Health, 94, 1141-1146. http://dx.doi.org/10.2105/AJPH.94.7.1141

[20] Clark, R.A., Kissinger, P., Bedimo, A.L., Dunn, P. and Albertin, H. (1997) Determination of Factors Associated with Condom Use among Women Infected with Human Immunodeficiency Virus. International Journal of STD and AIDS, 8, 229-233. http://dx.doi.org/10.1258/0956462971919976

[21] Dessie, Y., Gerbaba, M., Bedru, A. and Davey, G. (2011) Risky Sexual Practices and Related Factors among ART Attendees in Addis Ababa Public Hospitals, Ethiopia: A Cross-Sectional Study. BMC Public Health, 11, 422. http://dx.doi.org/10.1186/1471-2458-11-422

[22] Ncube, N.M., Akunna, J., Babatunde, F., Nyarko, A., Yatich, N.J., Ellis, W., et al. (2012) Sexual Risk Behaviour among HIV-Positive Persons in Kumasi, Ghana. Ghana Medical Journal, 46, 27-33.

[23] Sayles, J.N., Pettifor, A., Wong, M.D., MacPhail, C., Lee, S.J., Hendriksen, E., et al. (2006) Factors Associated with Self-Efficacy for Condom Use and Sexual Negotiation among South African Youth. JAIDS: Journal of Acquired Immune Deficiency Syndromes, 43, 226-233. http://dx.doi.org/10.1097/01.qai.0000230527.17459.5c

[24] Weller, S.C. (1993) A Meta-Analysis of Condom Effectiveness in Reducing Sexually Transmitted HIV. Social Science \& Medicine, 36, 1635-1644. http://dx.doi.org/10.1016/0277-9536(93)90352-5

[25] Peretti-Watel, P., Spire, B., Obadia, Y. and Moatti, J.P. (2007) Discriminations against HIV-Infected People and the Spread of HIV: Some Evidence from France. PLOS ONE, 2, e411. http://dx.doi.org/10.1371/journal.pone.0000411

[26] Wolitski, R.J., Pals, S.L., Kidder, D.P., Courtenay-Quirk, C. and Holtgrave, D.R. (2009) The Effects of HIV Stigma on Health, Disclosure of HIV Status, and Risk Behavior of Homeless and Unstably Housed Persons. AIDS and Behavior, 13, 1222-1232. http://dx.doi.org/10.1007/s10461-008-9455-4

[27] Varni, S.E., Miller, C.T. and Solomon, S.E. (2012) Sexual Behavior as a Function of Stigma and Coping with Stigma among People with HIV/AIDS in Rural New England. AIDS and Behavior, 16, 2330-2339. http://dx.doi.org/10.1007/s10461-012-0239-5

[28] Przybyla, S.M., Golin, C.E., Widman, L., Grodensky, C.A., Earp, J.A. and Suchindran, C. (2013) Serostatus Disclosure to Sexual Partners among People Living with HIV: Examining the Roles of Partner Characteristics and Stigma. AIDS Care, 25, 566-572. http://dx.doi.org/10.1080/09540121.2012.722601

[29] Heard, I., Potard, V., Costagliola, D. and Kazatchkine, M.D. (2004) Contraceptive Use in HIV-Positive Women. Journal of Acquired Immune Deficiency Syndrome, 36, 714-720. http://dx.doi.org/10.1097/00126334-200406010-00008

[30] Conserve, D., Sevilla, L., Younge, S., Mbwambo, J. and King, G. (2012) Condom Use among HIV-Positive Sexually Active Adults and Partner's HIV Status in Dares Salaam, Tanzania. Journal of Health Care for the Poor and Underserved, 23, 191-203. http://dx.doi.org/10.1353/hpu.2012.0010

[31] Shuper, P.A., Joharchi, N., Irving, H. and Rehm, J. (2009) Alcohol as a Correlate of Unprotected Sexual Behavior among People Living with HIV/AIDS: Review and Meta-Analysis. AIDS and Behavior, 13, 1021-1036. http://dx.doi.org/10.1007/s10461-009-9589-z

[32] Crepaz, N., Hart, T.A. and Marks, G. (2004) Highly Active Antiretroviral Therapy and Sexual Risk Behaviour: A Meta-Analytic Review. Journal of American Medical Association, 292, 224-236. http://dx.doi.org/10.1001/jama.292.2.224

[33] Van Devanter, N., Duncan, A., Birnbaum, J., Burrell-Piggott, T. and Siegel, K. (2011) Gender Power Inequality and Continued Sexual Risk Behavior among Racial/Ethnic Minority Adolescent and Young Adult Women Living with HIV. Journal of AIDS \& Clinical Research, S1, pii:003. http://dx.doi.org/10.4172/2155-6113.S1-003

[34] Awusabo-Asare, K., Anarfi, J.K. and Agyeman, D.K. (1993) Women’s Control over Their Sexuality and the Spread of STDs and HIV/AIDS in Ghana. Health Transition Review, 3, 69-83.

[35] Dixon-Mueller, R. (1993) The Sexuality Connection in Reproductive Health. Studies in Family Planning, 24, $269-282$. http://dx.doi.org/10.2307/2939221 